\title{
Watertight Door Control System on A Ship using Profinet IO
}

\author{
Monika Rybczak, Damian Radzimski, Natalia Wenta
}

\begin{abstract}
The paper is to deal with the analysis of Profinet IO networks based on the design of a watertight door control system on a passenger ship. The analysis was based on modernization of existing watertight door system installed on a ship. The currency system on ship it use old PLC like S7-200, receive and send date only serial communication. In laboratory on University conditions the same network using two controls company Siemens PLC S7-1214 DC/DC/DC and simulated HMI write on WinCC was recreated and modified with Profinet IO standard. The authors propose a novel watertight door control system using two controllers and a touch panel HMI. The control algorithms have been written in LAD language with use norm SOLAS about list alarm. Program it was write in TIA Portal with use Function blocks (FB) with Block Date (DB) and Function (FC). When designing the laboratory bench, the authors based their assumptions on the actual solutions used on the Balmoral passenger ship. Tests were carried out on parameters related to dimensions, including the length of cables between communication modules of controllers, giving in results the actual lengths of cables in the current system and the one proposed in this work. Then, the possibility of data exchange between the two controllers and the visualization of the simulated KTP 1200 panel was examined. The operation of the software was verified, including its optimization for the correct operation of the entire system. The final part of the paper, after verifying the performance of the system in three steps, an analysis of the current system and the novel solution based on Profinet IO network is given.
\end{abstract}

Keywords: Profinet IO, PLC, HMI, watertight door system.

\section{INTRODUCTION}

$\mathrm{O}_{\text {ver the last several years the use of PLCs }}$ (programmable logic control) in the marine industry has increased. They are used in many systems. At the turn of the last three years, articles have proposed them for ventilation control systems [1]. In the article describe [2] application of PLC use technology in automatic control devices of ship auxiliary machinery. An interesting solution was shared by the authors of [3] an exhaust gas desulfurization control system for the ship was designed based on the sodium-alkali desulfurization system. The results system used composed

Manuscript received on August 31, 2021.

Revised Manuscript received on September 22, 2021.

Manuscript published on September 30, 2021.

* Correspondence Author

Monika Rybczak*, Department of Ship Automation, Gdynia Maritime University, Gdynia, Poland. Email: m.rybczak@we.umg.edu.pl

Damian Radzimski, Department of Ship Automation, Gdynia Maritime University, Gdynia, Poland. Email: 43384@student.umg.edu.pl

Natalia Wenta, Department of Ship Automation, Gdynia Maritime University, Gdynia, Poland. Email: 43410@student.umg.edu.pl

(c) The Authors. Published by Blue Eyes Intelligence Engineering and Sciences Publication (BEIESP). This is an open access article under the CC BY-NC-ND license (http://creativecommons.org/licenses/by-nc-nd/4.0/) control system composed and the monitoring system used newest Siemens S7-1500. While in 2017 [4] an article about passenger safety used PLC MicroLogix 1000 in automatic control of gangway conveyor system was published regarding. In paper [5] authors proposed a reefer container monitoring system can acquire data from the device sensors whos utilizes the existing onboard power line(s). In this paper, the authors propose a control related to the safety of a passenger ship, where the system deals with the control of watertight doors. An important point in PLC operation is data exchange with other devices or other controllers $[8,9,10]$. Network cables are used for data exchange and communication between devices. The aim of the research was to modernize an existing watertight door control system, which consisted of replacing used device components as well as the whole data exchange technology from older type serial common to newer Profinet IO. The paper presents the assumptions of watertight door control system on Balmoral $\mathrm{v} / \mathrm{m}$ passenger ship. The present state of the system and a proposal of modernization of the controllers configured using Profinet IO network is shown. Control algorithms resulting from design assumptions are given, and simulation and analysis of system operation based on the existing solution with a proposal of a new one is demonstrated.

\section{THE SHIP SYSTEM}

\section{A. Balmoral $\mathbf{v} / \mathbf{m}$ passenger vessel parameters}

The project was developed based on the data of the passenger ship $\mathrm{m} / \mathrm{v}$ Balmoral. The following table 1 shows the key parameters of the passenger ship $\mathrm{m} / \mathrm{v}$ "Balmoral" provided by "Fred Olsen Cruise Lines".

Table. 1 Technical data of the ship $\mathrm{m} / \mathrm{v}$ "Balmoral" [6].

\begin{tabular}{|l|l|}
\hline Vessel name: & Balmoral \\
\hline IMO: & 8506294 \\
\hline Vessel type: & Passenger \\
\hline Year of production: & 1988 \\
\hline Flag: & Baham \\
\hline Tonnage gross: & $43537[\mathrm{t}]$ \\
\hline Total length: & $218.05[\mathrm{~m}]$ \\
\hline Length between risers: & $185.45[\mathrm{~m}]$ \\
\hline Width: & $28.21[\mathrm{~m}]$ \\
\hline Maximum number of passengers: & 1778 \\
\hline Number of crew: & 471 \\
\hline Maximum speed: & $20[\mathrm{w}]$ \\
\hline
\end{tabular}

\section{B. System Design Assumptions.}

The system design must comply with the standards of the SOLAS Convention (International Convention for the Safety of Life at Sea) [7]. 


\section{Watertight Door Control System on A Ship using Profinet IO}

As one of the elements directly responsible for the safety of crew and passengers of ships, watertight doors are subject to a number of restrictions in the SOLAS Convention. However, focusing on the door control system, it is necessary to refer to SOLAS regulation 15. This specifies the time within which doors should be closed, if they are closed from the bridge operator panel or locally. This time is not more than $60 \mathrm{~s}$ for remote closing and not more than $90 \mathrm{~s}$ for manual closing. In addition, it is recommended that closing of the door should not take less than $20 \mathrm{~s}$ and no more than $40 \mathrm{~s}$ when the ship is in upright position. Closing of the door must be preceded by an acoustic signal and a light for minimum 5 $\mathrm{s}$, but not more than $10 \mathrm{~s}$ before switching on the mechanism (Fig. 1).

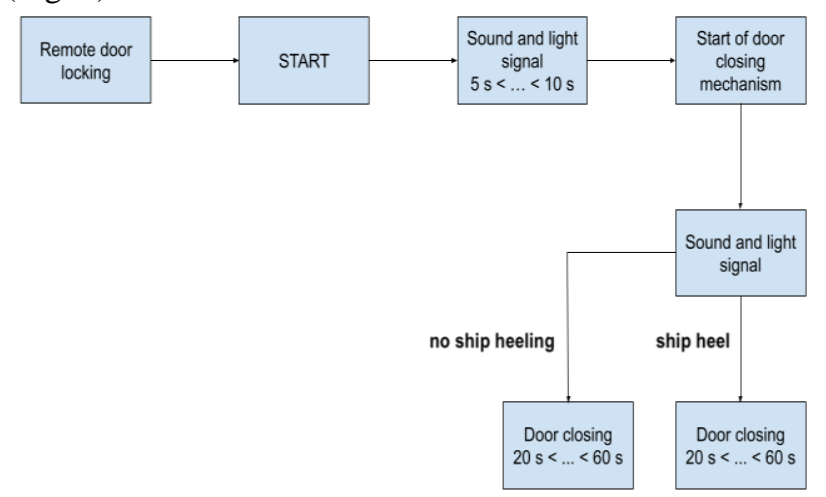

Figure 1 Locking of watertight doors according to SOLAS Convention (remote closing).

In addition, each remote closing station must be equipped with an indicator showing whether the door is closed or open. In addition to the restrictions on the watertight door closing system, the SOLAS Convention also specifies the type of drive that can be used to close the door. Closure cannot be accomplished by releasing the lock and the door dropping on its own. These propulsion systems must enable the doors to be completely closed when the ship heels up to $15^{\circ}$ to either side, and must be powered from the emergency switchboard directly or through switchboards. The same is true of the power supply for the control systems and the indicator and alarm circuits. In the case of manual closing, the levers enabling this shall be located on both sides of the door at a height of $1.6 \mathrm{~m}$ above the floor, and the direction of movement of the levers shall be in the direction of movement of the gates and shall be clearly marked. It includes requirements for door closing times and how to signal when the door is closing. The modernized project assumes using two Siemens controllers from S7-1200 family, which will communicate via Profinet network [10,11]. One master controller is located on the bridge and is responsible for displaying information and receiving commands from the user via the HMI panel. The second slave controller is located near the watertight door and is responsible for receiving commands from the master controller and transmitting information to the watertight door mechanisms. In addition, it receives any anomalies in the form of occurrence of possible malfunctions and transmits this data to the Master controller. The entire system depends on communication between devices. This is the most important part of the project because if the communication between the controllers or between the controller and the watertight door fails or malfunctions, the whole system will not work properly. The time it takes for information to be transferred from one device to another is also an important parameter. The old control system was based on Profibus network, while our system is based on Profinet network. Modernized system assumes using two S7-1200 controllers connected via Profinet network with connected HMI operator panel, which will be responsible for controlling system of 12 watertight doors.

\section{REVIEW CRITERIA}

\section{A. Ship system based on S7-200 series controler}

The watertight door control system that is currently on-board M/V Balmoral is based on old Siemens 226 $\mathrm{DC} / \mathrm{DC} / \mathrm{DC}$ controllers that are not networked together. The first controller located on the bridge is responsible for watertight door closing and related signaling. This controller has 6 modules extending the number of inputs and outputs. Connected to them are watertight door closing mechanisms, end sensors informing about the position of the gates, as well as the sound and light signalling. The second controller, located near the door on deck 3 , acts as an alarm channel. It has 6 input/output modules, which are connected to the binary measuring circuits informing about the occurrence of failures and the light and sound signaling. This solution forces the use of a large number of modules and cables (Fig. 2).

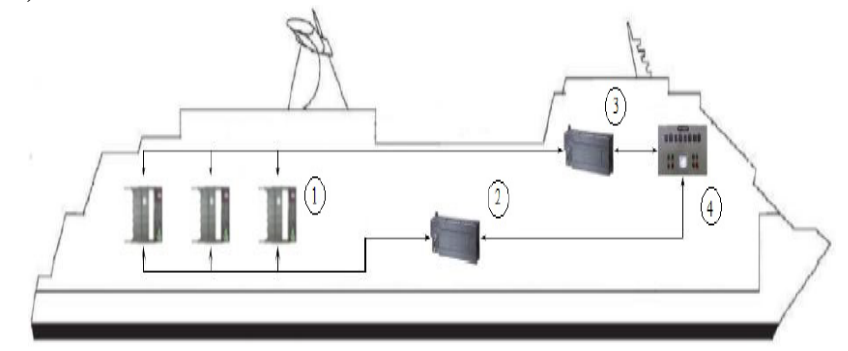

Figure 2 Illustrative connection diagram for a watertight door control system on ship - currency system

1 - watertight door; 2 - Siemens CPU 226 DC/DC/DC controller acting as an alarm channel; 3 - Siemens CPU 226 DC/DC/DC controller controlling the closing of the watertight door; 4 - operator panel;

\section{B. Proposed system solution based on S7-1200 family controllers}

The project consisted in modernization of the existing watertight door control system. Old S7-226 controllers were replaced by new Siemens CPU 1214 DC/DC/DC controllers, which communicate with each other using a modern Profinet network. In addition, the control system includes visualization of the watertight door control process based on Siemens SIMATIC HMI KTP1200 Comfort operator panel simulations. The first controller acting as master is located on the bridge with the operator panel connected to it. The panel enables remote closing of the watertight door, signals the occurrence of alarms and indicates the position of the gates. The second controller is located at the watertight door and is connected to it controlling the closing of the watertight door and also acts as an alarm channel. 
Both controllers are connected via Profinet network, due to the distance of more than 100m SCALANCE XC208 switch is used to transfer information between controllers. The switch ensures maximum data transfer regardless of the length of the Ethernet cable used (Fig. 3).

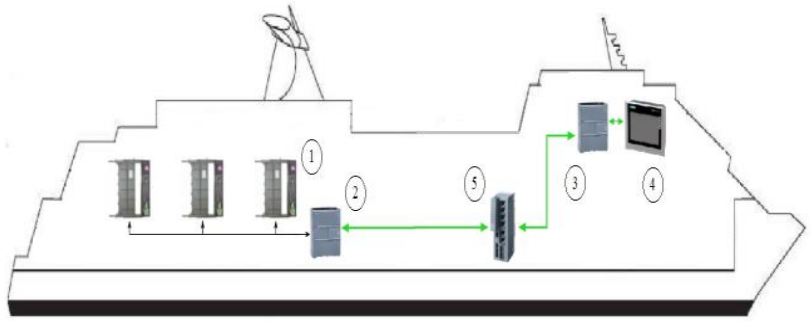

Figure 3 Overview of the upgraded watertight door control system - proposal newer system acting as Slave; 3 - Siemens CPU 1214C DC/DC/DC acting as Master; 4 - Siemens SIMATIC HMI TP1200 Comfort operator panel; 5 - SCALANCE Switch XC208;

\section{SYSTEM CONFIGURATION}

In order to properly control the watertight doors through the controllers along with using the HMI panel, you need to make the correct hardware configuration. Below is a proposed diagram of the connections between the Master and Slave (Fig.4).
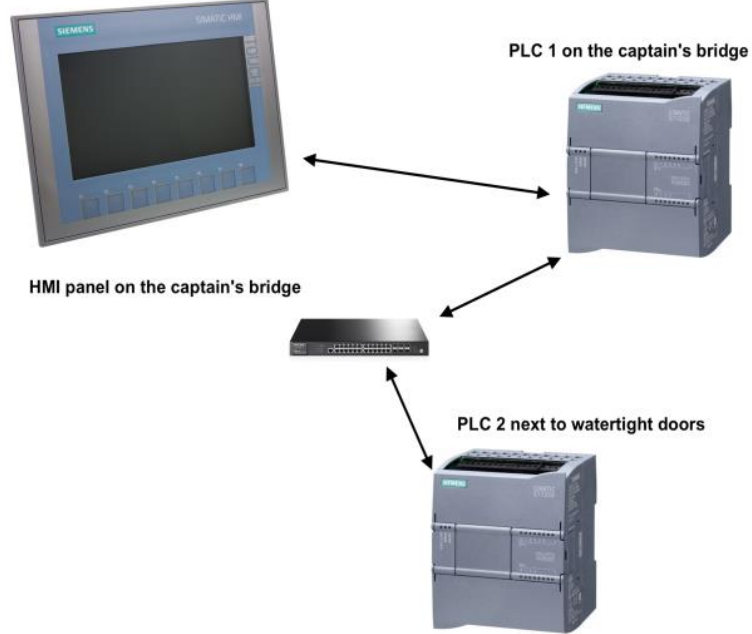

Figure 4 Proposal of a control system using two PLCs and HMI panel, working in PROFINET IO network. PLC 1 Master, PLC 2 - Slave.

The TIA Portal software was used to configure the PLCs and the HMI where the first thing to do is add the PLCs and the HMI (Fig. 5, Fig. 6, Fig.7).

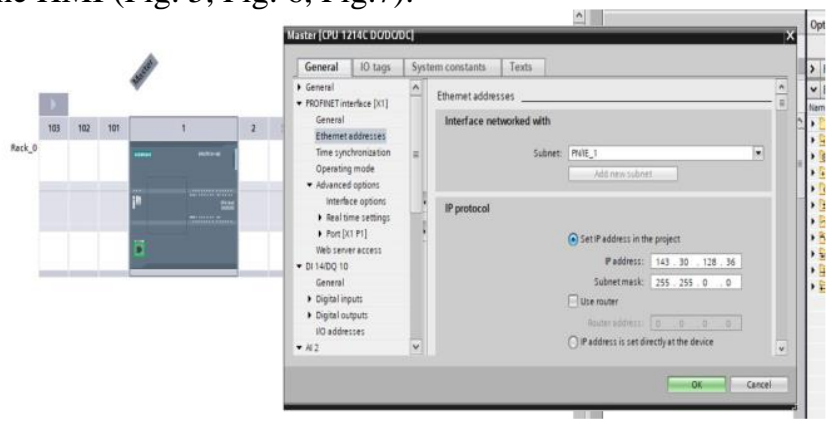

Figure 5 Assign IP address and subnet mask to the master controller. Step one to communication between PLCs.
1 - Watertight door; 2 - Siemens CPU 1214C DC/DC/DC

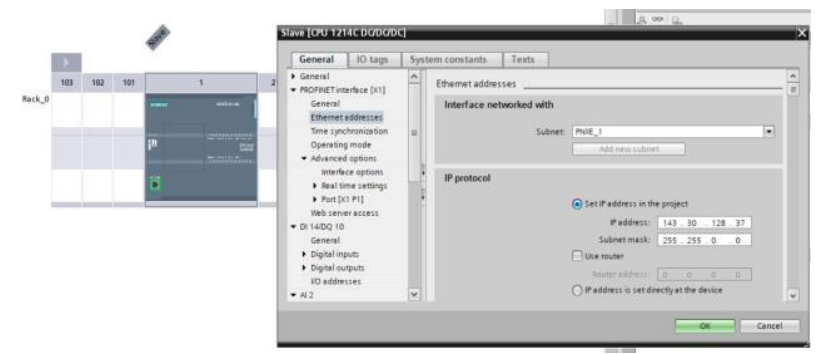

Figure 6 Assign IP address and subnet mask to slave controller. Step two to communication between PLCs.
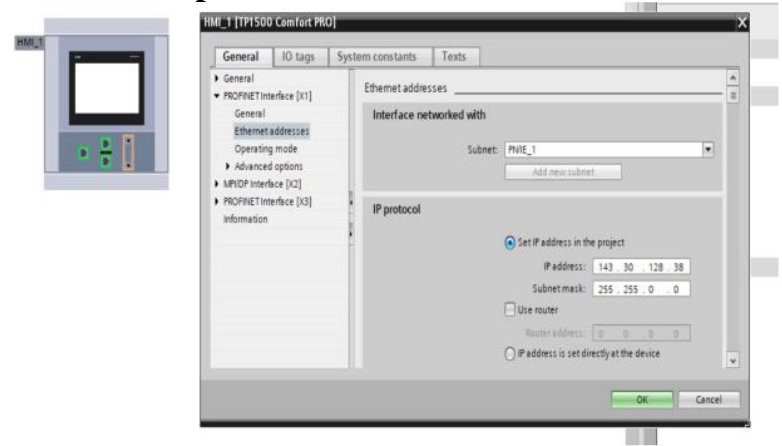

Figure 7 Assign IP address and subnet mask to HMI. Step three to communication between PLCs and HMI panel.

Once each device has been assigned an address, you need to connect these devices via the Profinet network. To do this, connect all devices in the Network View tab by dragging the lines from the ports marked green. At this point, the communication between the devices is already correct and they can work together over the Profinet network. PUT/GET communication is used to exchange data between the controllers. This is a one-way communication, i.e. the entire structure is located on one of the controllers, in this case the master controller. The first step to communication via PUT/GET is to enable this feature in the options of both controllers. This option can be found in Device Configuration/General/Properties/Protection \& Security/ Connection mechanisms (Fig.8). Next, check the connection in the S7 connection tab and connect the two controllers that are to exchange data with each other.

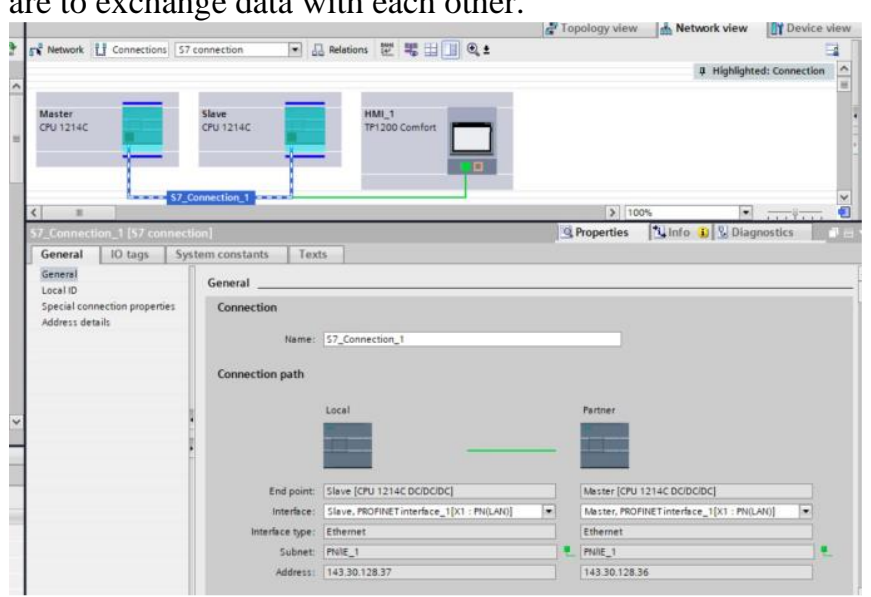

Figure 8 Finally connection of master and slave controllers for PUT/GET communication and with panel HMI.

Published By:

Blue Eyes Intelligence Engineering and Sciences Publication

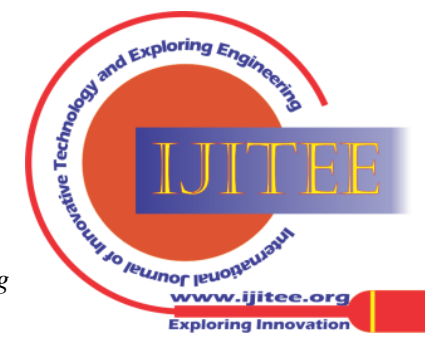




\section{Watertight Door Control System on A Ship using Profinet IO}

The last condition to correctly exchange data via PUT/GET is to add the PUT and GET blocks themselves, which can be found in the library on the Communication tab, and set the appropriate parameters and variables in them.

\section{STEP OF CONTROL PLC}

The operating graph of the system is too complicated; however, two figures are shown below. The first one contains a set of functions written for the master, that is PLC 1 (Fig.9).

\section{OB1 PLC 1: MASTER}

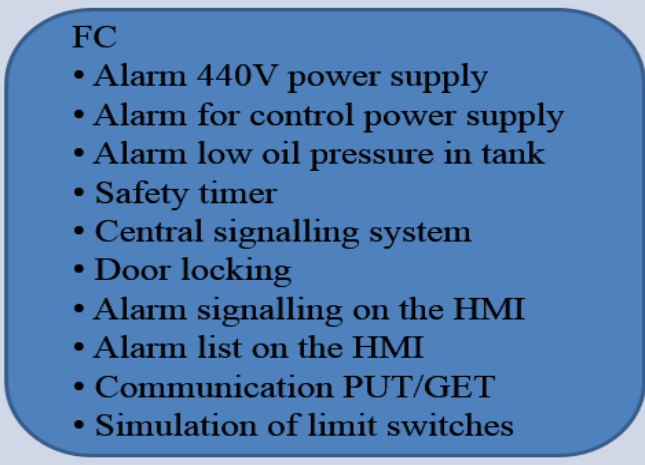

Figure 9 A list of functions of the program written for Master.

The "Master" controller is the master unit and it is in this unit that the main part of the program is located. The program uploaded to this unit is to communicate with the "Slave" controller, the central signaling system and the HMI panel, to enable remote closing of the doors, as well as to implement the algorithms associated with the alarm channels.

The second figure shows the list of programs stored using Function Block assigned to PLC 2 Slave (Fig.10).

\section{OB1 PLC 2: SLAVE}

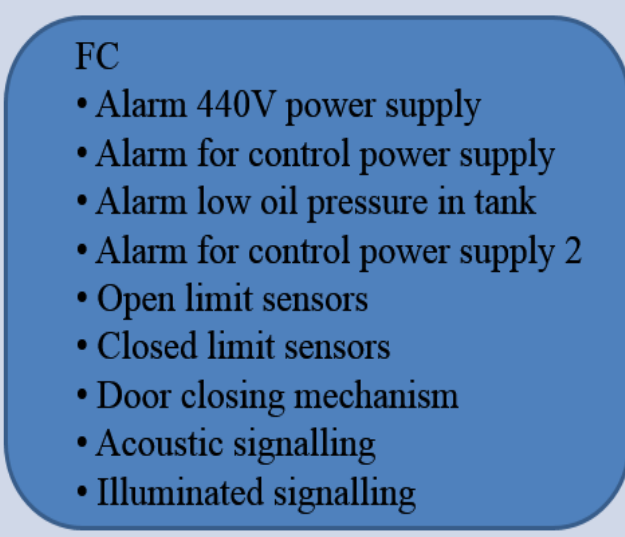

Figure 10 List of functions of the program written for the slave.

The "Slave" controller as a subordinate unit to the "Master" controller does not have algorithms that perform the main functions of the watertight door control system. The program included in this controller is only used to assign inputs with corresponding memories and to transfer information received from the "Master" unit to specific outputs of the "Slave" controller.

\section{RESULT AND DISCUSSION}

The project was based on two controllers, the first PLC 1 Master contains 18 FB blocks and 394 variables. The second PLC 2 Slave contains 9 FB blocks and 247 variables. The entire program fits on 276 A4 pages. The program meets all SOLAS standards. Autors used verification and validation like $(\mathrm{V} \& \mathrm{~V})[12,13]$. After connecting all the necessary components of the control system, configuring their communication and creating visualization on the operator panel, verification of the correct operation of the watertight door control system should be performed (Fig.11).

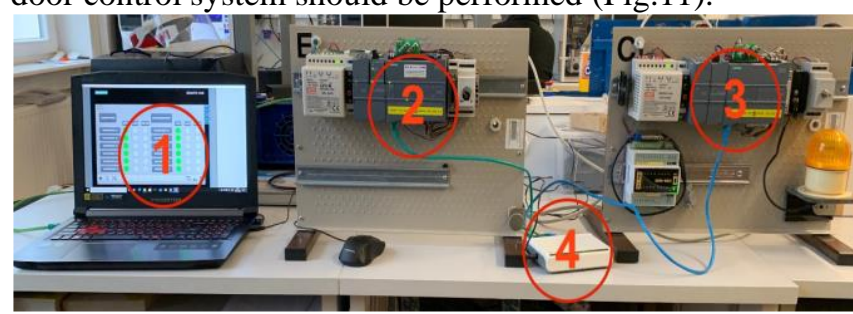

Figure 11 Test stand made to control watertight doors newer system, proposal autors.

On the figure (Fig. 11) saw red numbers: 1 - Laptop simulating the work of the operator panel Siemens SIMATIC HMI KTP1200 Comfort; 2 - Siemens 1214C DC/DC/DC controller acting as "Master"; 3 - Siemens 1214C DC/DC/DC controller acting as "Slave"; 4 - Switch replacing the Switch SCALANCE XC208;

After the implementation of the project was attempted to perform tests during the simulation in a laboratory environment the following steps:

- Correctness of driver configuration

- Correctness of the operator panel configuration

- Correctness of network communication configuration

- Alarm detection

- Remote door closing

Two Siemens 1214C DC/DC/DC controllers, a switch, and a laptop simulating an operator panel were used to verify the proper operation of the watertight door control system (Fig.11).

\section{A. Verify communication between devices on the Profinet IO network.}

Verification of correct connections is related to verification of communication. Verify that the communication of the devices over the Profinet network is working properly and that the devices are communicating and exchanging data with each other. Green color indicates correct configuration of the Profinet IO network (Fig.12).

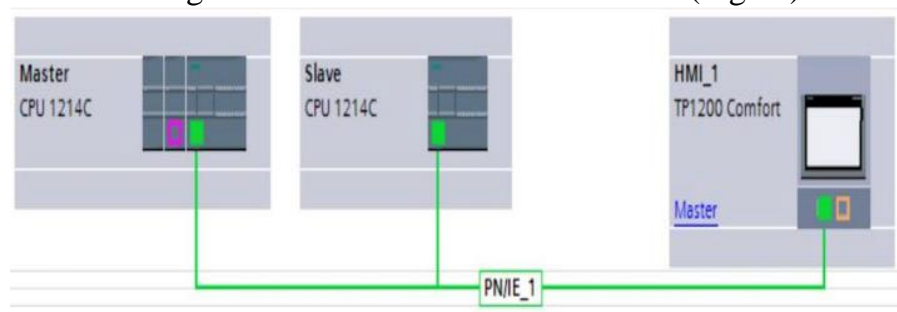

Figure 12 A screenshot of the configuration screen for correct communication of devices in a Profinet IO network.

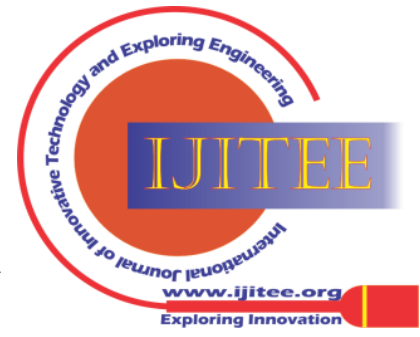


The figure gives a screenshot of the "Close door" instruction, where primarily all data exchange has occurred. Also, the green color indicates the exchange of information between the reading device and the executing device (Fig. 13).

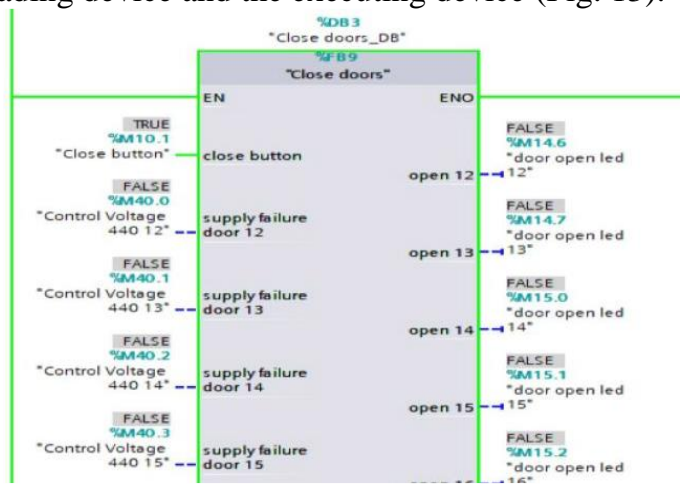

Figure 13 Verification of the correct operation of the watertight door closing program

\section{B. Verification of remote closing of watertight doors}

To check the correct operation of the remote closing of the watertight door, start the visualization on the operator panel and check the following signaling when the watertight door is open Fig.14).

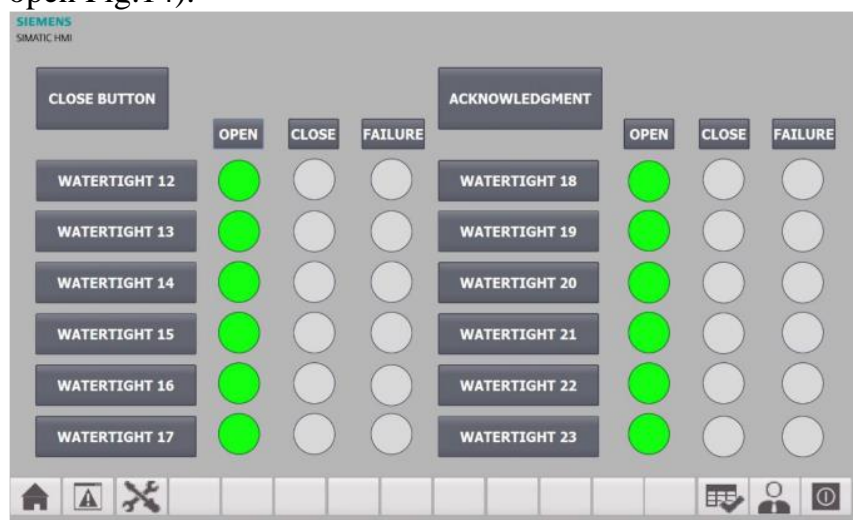

Figure 14 Verification of the correctness of the indication of an open watertight door

Of course, the same command applies to checking if the door is locked.

\section{Analysis of old and new watertight door control system.}

After performing the basic procedures and checking the connections as above, the authors provided a table that analyzed the current (old) system with the upgraded (new) system.(Table 2)

Table. 2 Comparison of the old and new watertight door control system

\begin{tabular}{|c|c|}
\hline $\begin{array}{l}\text { OLD WATERTIGHT } \\
\text { DOOR CONTROL } \\
\text { SYSTEM (PRESENT ON } \\
\text { THE SHIP) }\end{array}$ & $\begin{array}{l}\text { NEW WATERTIGHT DOOR } \\
\text { CONTROL SYSTEM }\end{array}$ \\
\hline $\begin{array}{l}2 \text { Siemens controllers } \\
\text { S7-226 }\end{array}$ & $\begin{array}{l}2 \text { Siemens controllers } \\
\text { S7-1214C }\end{array}$ \\
\hline Serial communication & $\begin{array}{c}\text { Communication using the latest } \\
\text { technology Profinet network based on } \\
\text { PUT/GET instructions }\end{array}$ \\
\hline $\begin{array}{l}\text { Physical signaling based on } \\
\text { LEDs and switches, and } \\
\text { system operation using } \\
\text { switches } \\
\end{array}$ & $\begin{array}{l}\text { HMI operator panel to reduce the } \\
\text { number of input/output modules needed }\end{array}$ \\
\hline $\begin{array}{l}\text { Total number of I/O } \\
\text { modules used: } \mathbf{1 2}\end{array}$ & $\begin{array}{c}\text { Total number of I/O modules used: } \mathbf{5} \\
\text { ET200S modules }\end{array}$ \\
\hline Serial cables & RJ45 shielded cables for connection \\
\hline
\end{tabular}

\begin{tabular}{||c|c||}
\hline $\begin{array}{c}\text { Problem with access to } \\
\text { spare parts for S7-200 } \\
\text { controllers }\end{array}$ & \begin{tabular}{c} 
to Profinet \\
\hline $\begin{array}{c}\text { Use of approx. 20 km total } \\
\text { cable length from the } \\
\text { controllers }\end{array}$
\end{tabular} \\
$\begin{array}{c}\text { Use of } \mathbf{0 . 2} \mathbf{~ k m} \text { total cable length } \\
\text { between controllers }\end{array}$ \\
$\begin{array}{c}\text { Applied devices are not } \\
\text { designed for operation on ships }\end{array}$ & $\begin{array}{c}\text { All elements are compliant with } \\
\text { standards and have certificates of } \\
\text { classification societies i.e.: Lloyd's } \\
\text { Register of Shipping needed to work on a } \\
\text { ship }\end{array}$ \\
\hline \hline
\end{tabular}

\section{CONCLUSION}

The project was made on the basis of data from $\mathrm{v} / \mathrm{m}$ Balmoral. It was carried out in the laboratory of the Maritime University of Gdynia, while all the verifications were performed on the basis of the built test bench and computer simulations. Modernization of the system design was carried out using TIA Portal V15 programming environment and WinCC (creation of visualization design for watertight door control system). The program was written entirely in LAD language (Ladder Logic). The program used the same solutions for all 12 watertight doors, regarding their remote closing, signaling the occurrence of alarms and information from limit sensors about the current position of sliders (door open, door closed, door in the process of closing). The solutions used in the program are based on those of the existing control system, but contain numerous corrections and improvements. The project consists of 27 FB blocks, 641 variables, 3 visualization screens, and the whole is contained on 276 A4 pages. It was found that the use of the TIA Portal environment together with dedicated controllers and an operator panel of the same company (Siemens) simplified the process of communication and connection of the entire control system. The tested configuration solutions were achieved, what is more according to the authors should minimize the costs. Further research should be extended to include the use of Internet 4.0 solutions, which could be associated with the remote control of the proposed system from the website based on the extension of the system with a router such as Secomea, with which the company Siemens cooperates.

\section{ACKNOWLEDGMENT}

Funding: The project is financed in the framework of the program by the Ministry of Science and Higher Education called "Regionalna Inicjatywa Doskonałości" in the years 2019-2022 (project number: 006/RID/2018/19; the sum of financing: 11,870,000 PLN).

\section{REFERENCES}

1. Ling, Sun. "Study on the Design of the Ventilation of Ship Engine Room Control System." Advanced Materials Research. Vol. 1061. Trans Tech Publications Ltd, 2015, pp. 908-911.

2. GAO, Meirong. Application Analysis of PLC Technology in Automatic Control of Ship Auxiliary Machinery. Journal of Coastal Research, 2020, 115.SI: 130-132. 
3. YIN, Qi, et al. Design of ship exhaust gas desulfurization control system based on S7-1500 PLC. In: Journal of Physics: Conference Series. IOP Publishing, 2019. p. 032083.

4. Veerakumar, P., M. Dheepak, and S. V. Saravanan. PLC Based Automatic Control for Onboard Ship Gangway Conveyor System." International Journal of Mechanical Engineering and Technology 8.3 2017: pp. 229-235.

5. HUH, Jun-Ho. Reefer container monitoring system using PLC-based communication technology for maritime edge computing. The Journal of Supercomputing, 2020, 76.7: 5221-5243.

6. Fred Olsen Crusie Line ship Balmoral: http://www.fredcruises.co.uk/balmoral-cruises/ - informacje dotyczące statku m/v „Balmoral”. Access: 29.08.2021r.

7. User manual for watertight sliding doors, 15-A10871;

8. A. M. Tonello and F. Versolatto, "Bottom-Up Statistical PLC Channel Modeling-Part II: Inferring the Statistics", IEEE Trans. Power Del., vol. 25, no. 4, pp. 2356-2363, October 2010.

9. Barmada S, Bellanti L, Raugi M, Tucci M (2010) Analysis of power-line communication channels in ships. IEEE Trans Veh Technol 59(7):3161-3170

10. Antoniali M, Tonello AM, Lenardon M, Qualizza A (2011) Measurements and analysis of PLC channels in a Cruise Ship. IEEE International Symposium on Power Line Communications and Its Applications, Udine, pp 102-107

11. P. Ferrari, A. Flammini and S. Vitturi, "Performance analysis of PROFINET networks", Comput. Standards Interfaces, vol. 28, pp. 369-358, Apr. 2006.

12. G. Frey and L. Litz, "Formal methods in plc programming", Proc. of IEEE Conference on System Man and Cyber-netics Nashville, pp. 2431-2436, oct 2000.

13. Rich Harwell, Eaton Corporation "The integrated HMI-PLC" ,Industry Application IA05003001E Effective August 2012

\section{AUTHORS PROFILE}

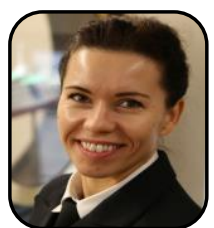

Monika Rybczak. She received her Ph.D. degree in UMG from Maritime University in Gdynia, Poland, in 2016. She works in laboratory Programmable Logical Control, Visualization Process and Industrial Computer Network. Gdynia, Poland and his research interests include UMG.

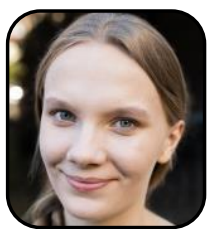

Wenta Natalia. Completed engineering studies, currently in the process of master's studies on UMG. Student of the HMI research club:

https://www.facebook.com/Ko\%C5\%82o-Naukowe-HMI-19835233952192 25/. Works at the Remontowa Shipyard.

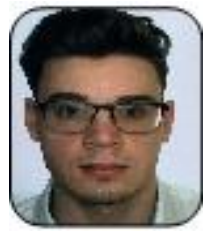

Radzimski Damian. Completed engineering studies, currently in the process of master's studies on UMG. Student of the HMI research club:

https://www.facebook.com/Ko\%C5\%82o-Naukowe-HMI-19835233952192 25/ Works at the Remontowa Shipyard.

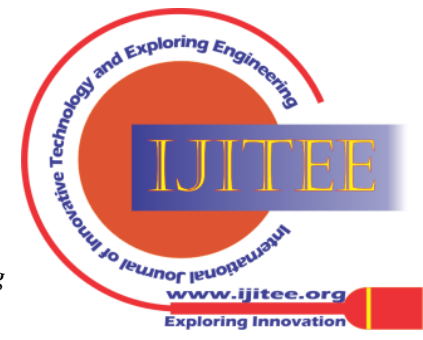

